\title{
LA NOCIÓN POSITIVA DE CIENCIA DE PAUL KARL FEYERABEND
}

\author{
María Teresa Gargiulo de VÁzquez \\ CONICET \\ Universidad Nacional de Cuyo \\ gargiulomteresa@gmail.com
}

RESUMEN: El pensamiento de Feyerabend ha sido objeto de múltiples y divergentes interpretaciones, entre las que parece ser unánime la inscripción de su obra dentro de las coordenadas de un escepticismo radical. Estas lecturas encuentran parcialmente sustento en su anarquismo epistemológico, el cual constituye en sí mismo una reducción al absurdo de los intentos del positivismo lógico y del racionalismo crítico de definir axiomática o metodológicamente la ciencia. En este sentido, su obra puede ser entendida, en parte, como una argumentación negativa y escéptica con respecto a aquellas nociones de ciencia. No obstante, esta hermenéutica no deja de ofrecer una visión fragmentaria y parcial de su pensamiento. El propósito de este artículo es reconstruir el itinerario intelectual a partir del cual Feyerabend va madurando su comprensión positiva de la ciencia para trascender las hermenéuticas de su obra en la clave del escepticismo.

PALABRAS CLAVE: anarquismo epistemológico, relativismo, mito, filosofía, ciencia humana

SUMMARY: Feyerabend's thought has been the object of multiple and divergent interpretations, but amongst these the inscription of his work within the coordinates of a radical skepticism seems to be unanimous. These readings find partial support in his epistemological anarchism, which constitutes a reductio ad absurdum of the attempts of logical positivism and critical rationalism to define science axiomatically or methodologically; in this sense his work can be treated as a set of negative and skeptical arguments concerning those notions of science. However, this hermeneutic offers only a fragmented and partial view of his thought. The purpose of this article is to reconstruct the intellectual journey along which Feyerabend matures his positive understanding of science in order to transcend the hermeneutics of his work in the key of skepticism.

KEY WORDS: epistemological anarchism, relativism, myth, philosophy, human science

\section{Introducción}

La actitud escéptica que muestra Feyerabend en sus habituales razonamientos por reducción al absurdo han llevado a críticos como Neto (1991), Musgrave (1978, p. 192), Watkins (2000, pp. 339-344), Hooker (1991, p. 96), Kadvany (1996), Reaven (2000, p. 23) y, por supuesto, a Preston (2000), a reconocerlo como uno de los representantes que da cumplimiento al objetivo de desestabilizar y deconstruir 
la ciencia. Acusan al vienés de abanderar un escepticismo por el cual es incapaz de ofrecer una explicación de la ciencia alternativa a las que rechaza. Hooker escribe:

Feyerabend ha subrayado [que] el uso de una reductio ad absurdum no es un compromiso a creer en sus premisas. Entonces, no puedo condenar los presupuestos formalistas tácitos de Feyerabend simplemente observando la crudeza de sus formulaciones. Pero, entonces, la gente razonable tiene derecho a pedir una explicación positiva que sustituya aquello que ha sido rechazado. El hecho mismo de que Feyerabend no ofrezca ninguna, y que lo que él realmente ofrece permanece dentro de las formulaciones ordinarias empleadas en sus propias reducciones, sugiere que él de hecho está limitado por sus presuposiciones tácitas. $\left(1991\right.$, p. 96) ${ }^{1}$

Preston utiliza un argumento similar y sostiene que el vienés lejos de proponer una teoría o una comprensión positiva de la ciencia, se limita a criticar o a desestabilizar lo modelos científicos que ofrecen sus interlocutores, concretando así la filosofía deconstructiva de Derrida. Y concluye que a Feyerabend no le interesa elucidar la ciencia sino destruirla:

El filósofo posmoderno no tiene interés en "esclarecer" la ciencia. [...] Las últimas obras de Feyerabend, me parece, se ajustan a esta descripción bastante bien. Nunca se interesó por "aclarar" o simplemente explicar las actividades de los agentes de primer orden. En sus obras anteriores, su objetivo declarado era introducir el progreso científico dentro de la filosofía. En su posterior encarnación, como es bien sabido, entierra esta concepción científica de la filosofía (aunque nunca desaparece totalmente), debajo de una cosmovisión posmoderna. (2000, pp. 88-89)

Sea o no justa la interpretación de Preston acerca de la obra tardía de Feyerabend, ésta parece haber ofrecido una clave de lectura que ha ido imponiéndose paulatinamente en los críticos y especialistas en nuestro autor. Al igual que Preston, Adolfo Vásquez Rocca (2005) caracteriza el escepticismo del vienés como el descreimiento radical de la posibilidad de acceder a interpretaciones validadas a través de un criterio externo o distinto a la ficcionalización de los relatos. También Mario Bunge en su libro Cápsulas (2003, p. 27) identifica la consigna "Todo vale" de su anarquismo epistemológico con las tesis del pensamiento débil. Los críticos interpretan el anarquismo como la defensa

${ }^{1}$ La traducción de todas las citas de este artículo es mía. 
de una visión relativista e irracional de la ciencia. Neto (1991), por su parte, afirma que el anarquismo de Feyerabend es análogo al escepticismo de los antiguos griegos, pues al utilizarlo puede argumentar a favor de cualquier posición. Por otro lado, Musgrave (1978, p. 192) sostiene que su anarquismo supone "la tesis de que cualquier teoría o programa de investigación es tan bueno como cualquier otro", entonces parece que según su anarquismo epistemológico no hay nada que pueda ser llamado ciencia o, lo que es lo mismo, que todo pueda llamarse científico.

El anarquismo epistemológico que Feyerabend formula en los años setenta es una reducción al absurdo de las interpretaciones tradicionales de la ciencia, es decir, de los intentos de definir axiomática o metodológicamente a la ciencia. Si atendemos a esta forma de argumentar críticamente parecería justo situar su pensamiento - tal como hacen los críticos mencionados- en el marco de un escepticismo o deconstructivismo radical. Particularmente porque su doctrina de la inconmensurabilidad y su anarquismo epistemológico podrían ser entendidos como una mera radicalización de las consecuencias absurdas que se siguen de los supuestos de sus interlocutores. Pero, sobre todo, porque con ellas lo que hace es denunciar la ausencia de un fundamento o metacriterio para evaluar la ciencia y las demás tradiciones de pensamiento.

No obstante, cabe subrayar que ni el anarquismo ni la doctrina de la inconmensurabilidad representan su concepción positiva de la ciencia. $^{2}$ A través de éstos el vienés se limita a demostrar que si se aceptan las interpretaciones tradicionales de la ciencia se debe reconocer que los episodios más significativos de la historia de la ciencia son irracionales. Mas, insistimos, esto no supone que conciba positivamente a la ciencia como una empresa irracional. Lo que quiere mostrar es que la ciencia presenta este atributo en la medida en que intentamos comprender el quehacer científico según los cánones tradicionales de los filósofos de la ciencia.

Feyerabend no es escéptico con respecto a la racionalidad, sólo se opone a un modelo particular de racionalidad que adscribe al método la garantía del éxito científico. El filósofo busca reducir este modelo de racionalidad al absurdo mediante la siguiente argumentación: la racionalidad científica exige adoptar un método. Pero el método frecuentemente obstaculiza el éxito de la ciencia; luego el éxito de la

${ }^{2}$ Para analizar el anarquismo epistemológico y la doctrina de la inconmensurabilidad de Paul Feyerabend como reducciones al absurdo de las tesis del positivismo lógico y del racionalismo crítico, véase Gargiulo 2014a, 2014b y 2015b. 
ciencia exige abandonar la racionalidad científica y asumir el principio "todo vale". Ahora bien - concluye Feyerabend - si todo vale, entonces nada vale, ni siquiera el método, lo cual es evidentemente un absurdo. El "todo vale" no es sino un jocoso e irónico resumen de la sorpresa de un racionalista cuando descubre la ausencia de un criterio metodológico universalmente aplicable a la ciencia. Expresa la conclusión que obligadamente alcanza el racionalista cuando descubre la complejidad del quehacer científico.

En un argumento por reducción al absurdo el autor no manifiesta compromiso alguno, no toma una posición definida en el asunto que se discute. Sin embargo, esto no implica que carezca en absoluto de un posicionamiento frente a la cuestión que se debate. Por lo tanto, es justo destacar que se ofrecería una caracterización incompleta de la obra de Feyerabend si se expusiera únicamente como una reducción al absurdo de las premisas del positivismo lógico o del racionalismo crítico, pues tal y como lo explica Munévar (2000, p. 65) su obra no puede reducirse a una filosofía escéptica o negativa, sino que además debe entendérsela como la búsqueda de un progreso científico más humano. En su ensayo Contra el método (1989/1970, pp. 148-149) ${ }^{3}$ el vienés postula su pluralismo teórico como una posible vía para concretar una ciencia más humana. Afirma que la coexistencia en el quehacer científico de una pluralidad de concepciones del mundo que trasciendan incluso los límites del naturalismo cientificista es el único modo de poder medir las consecuencias humanas de sus logros y resultados.

En sus escritos encontramos que los argumentos por reducción al absurdo que utiliza la filosofía de la ciencia tradicional se entrelazan, a su vez, con sugerencias positivas acerca de cómo debe ser la ciencia. En la introducción que precede al volumen I y II de sus Philosophical Papers, Feyerabend (1981d) formula la noción de "dos cadenas argumentativas" para explicar el contenido tanto de sus artículos escritos en la década de los años cincuenta como de aquellos que aparecían por primera vez en dichos compendios. ${ }^{4}$ La primera cadena argumentativa - explica el vienés - es crítica, es decir, en ella no

${ }^{3}$ Para facilitar la lectura cronológica de las obras de Paul Feyerabend, tanto las fechas en las citas como en la bibliografía tendrán doble fecha. La primera se refiere la publicación consultada y la segunda es el año de la primera publicación. La intención es dar cuenta de un orden cronológico de las publicaciones y, al mismo tiempo, remitir al lector a los lugares precisos donde pueda cotejar las citas textuales, las paráfrasis y las referencias generales.

${ }^{4}$ Para una discusión crítica acerca de estas dos cadenas argumentativas en Feyerabend, véanse Jary 1991 y Farrell 2003 (pp. 195-199). 
se aceptan los fenómenos, procesos o instituciones, sino que, por el contrario, se examinan y se procura modificarlos ( $c f r$. 1981d, p. ix). Esta cadena constituye el camino negativo por el cual descubre las contradicciones y limitaciones de la concepción heredada y del racionalismo crítico, en sus intentos de definir la ciencia discriminándola dialécticamente de la metafísica. Estos argumentos podrían ser leídos en clave escéptica y deconstructivista - tal como hace la literatura que se mencionó anteriormente-

En cuanto a la segunda cadena argumentativa, Feyerabend comienza con la elección de una visión comprensiva del universo y formas de vida. En este sentido, sugiere adaptar las ideas y hábitos a las intuiciones o percepciones de la tradición elegida: "se decide considerar como reales aquellas cosas que desempeñan un papel importante en el tipo de vida que hemos elegido" (1981d, p. xiii). De aquí que de acuerdo con las mismas instrucciones del vienés su obra no puede interpretarse únicamente como una reducción al absurdo de determinados modelos de ciencia. Sus escritos también ofrecen, a través de este segundo tipo de cadena argumentativa, una propuesta positiva de la ciencia, la racionalidad científica y la civilización.

La obra de Feyerabend no acaba en la mera denuncia o en la reducción al absurdo; propone positivamente un modelo de ciencia alternativo a aquellos que son objeto de sus diatribas y denuncias. Luego, y a pesar del acierto parcial de las hermenéuticas en clave deconstructivista mencionadas con anterioridad, creemos que éstas corren el peligro de ofrecer una lectura fragmentaria e incompleta de la obra del vienés, pues cada uno de los elementos de su obra, a saber, su doctrina de la inconmensurabilidad, su pluralismo teórico y su anarquismo epistemológico, pueden leerse y analizarse efectivamente como reducciones al absurdo de las nociones tradicionales de ciencia de aquella época. No obstante, también deben interpretarse como instancias positivas de su itinerario intelectual, es decir, como oportunidades que le permitieron entrever direcciones y caminos para acceder a una visión más comprensiva y realista de la dinámica científica. En otras palabras, las consecuencias absurdas que nuestro epistemólogo infiere de la posición de sus contrincantes le indican de forma negativa que en esa dirección no se encuentra una apropiada comprensión de la ciencia. ${ }^{5}$

${ }^{5}$ Cabe aclarar que el vienés nunca pretendió elaborar una filosofía a modo de un sistema abstracto que establezca una respuesta conclusiva, universal y necesaria acerca de la ciencia, la sociedad, la cultura y el mito. Por el contrario, insiste en que su obra se lea como un ensayo periodístico ( $c f r .2003 / 1991$, p. 182) más nunca 
El objetivo de este trabajo es trascender las hermenéuticas deconstructivistas y escépticas de su obra, para lo cual analizaremos diversas tesis o elementos de sus escritos en tanto éstos le permitieron acceder y madurar su comprensión positiva de la ciencia. El itinerario intelectual a través del cual Feyerabend va madurando su comprensión de la ciencia se plasma fundamentalmente en tres tesis que justifican a su vez la división del artículo. La primera dicta la unidad intrínseca que la ciencia guarda con el mito, el arte y la filosofía (1). La segunda establece la ciencia como una tradición alternativa entre otras (2). Finalmente, una tercera tesis donde postula la ciencia como manifestación de un Ser abundante (3). Estas tesis son, a mi entender, las tres grandes instancias que caracterizan positivamente su concepción de la ciencia.

La consideración de estas tres grandes tesis no responde a una secuencia estrictamente temporal, sino más bien al estilo dialéctico con el cual Feyerabend desarrolla su pensamiento. El orden expositivo de este trabajo no busca respetar un orden estrictamente cronológico; la exposición es más bien hermenéutica y comprensiva. Evidentemente con el fin de manifestar cómo Feyerabend va madurando su concepción propia acerca de la ciencia, he visto conveniente distinguir y mencionar la etapa y las obras en las que expone respectivamente cada una de estas tesis. No obstante, hay que tener presente que este autor con frecuencia rompe la línea histórica, como él mismo lo reconoce en su autobiografía, pues suele utilizar ideas que ya ha expresado en trabajos anteriores para defender nuevos puntos de vista. ${ }^{6}$ De aquí la decisión de abordar estas tres tesis de modo que sean particularmente patentes las distintas oscilaciones y puntos de vista de nuestro autor. ${ }^{7}$

\section{Mito, filosofía y ciencia}

A través de su anarquismo epistemológico Feyerabend busca demostrar las contradicciones y limitaciones que los intentos del neopositivismo lógico y del racionalismo crítico suponen de establecer un

como un sistema filosófico (cfr. 1992/1975, pp. 16-17). Dicha insistencia manifiesta su reticencia a formular un nuevo modelo prescriptivo de ciencia que repita los parámetros y cánones universales propios del racionalismo científico. No obstante, esto no implica que no haya esbozado, aunque de un modo no racionalista, algunas respuestas positivas a las cuestiones que se planteó a lo largo de su vida.

${ }^{6}$ En su autobiografía escribe "AM [Against Method] no es un libro, es un collage. Contiene descripciones, análisis y argumentos ya publicados, casi con las mismas palabras, diez, quince y aun veinte años antes" (Feyerabend 1995, p. 139).

${ }^{7}$ Véase la nota 3 de este texto. 
criterio de demarcación que defina qué es la ciencia. Da cuenta de cómo aquellos elementos frente a los cuales aquellos procuran delimitar una definición negativa de ciencia constituyen paradójicamente el seno del quehacer científico. Al destacar la presencia de la metafísica o el mito en la ciencia Feyerabend no pretende denostar la ciencia, tal como sus críticos apuntan habitualmente, sino demostrar que es falsa la dialéctica que el racionalismo crítico y el positivismo lógico establece entre ciencia y metafísica.

Lo que me interesa destacar particularmente en este primer punto es cómo dicha argumentación constituye el punto de partida de una nueva concepción de ciencia por parte del vienés. Su refutación de los distintos criterios de demarcación establece el eje sobre el cual comienza a esbozar positivamente su comprensión de la ciencia. A saber, una visión de la ciencia donde el mito, el arte y la filosofía la integran y constituyen junto con ella un único proceso histórico a partir del cual se configura la entera cultura occidental. En un sentido positivo, se puede decir que Feyerabend concibe la ciencia como la continua comunicación de múltiples e incluso antagónicas tradiciones. Desde esta nueva comprensión de la ciencia cuestiona la noción unívoca de la racionalidad científica postulada por la filosofía de la ciencia de aquel entonces.

A lo largo de sus artículos publicados entre los años 1955 y 1968, Feyerabend presenta a las cosmologías y los mitos como aquellos elementos metafísicos que no son susceptibles de un examen mediante un método definido. Los explica como aquellas vagas suposiciones sobre el mundo que carecen del vigor formal que sí poseen, en cambio, las teorías científicas. Fiel a una tradición popperiana nuestro epistemólogo inscribe al mito en un estadio precientífico en la medida en que no posee originariamente un contenido susceptible de falsación empírica. Para que el mito devenga en ciencia, éste debe formularse de modo que sea posible especificar un resultado experimental preciso que pueda ponerlo en peligro u obligarnos a abandonarlos, pero, hasta ese momento, ni el mito ni la filosofía parecerían estar originariamente — según el vienés (1981h, pp. 36, 43) - al mismo nivel que la ciencia.

A finales de los años setenta, y como resultado de su primera versión del pluralismo metodológico y de sus estudios culturales comparados, Feyerabend emprende una revisión crítica de su propia formación en el racionalismo popperiano y, por ende, de esta categorización precientífica del mito y la filosofía. Utilizando distintos argumentos por reducción al absurdo muestra las paradojas que se siguen de los 
intentos de restringir lo mítico o lo metafísico a un estadio precientífico.

Su pluralismo metodológico constituyó una oportunidad para demostrar metodológicamente la presencia ineludible y positiva que desempeñan en el quehacer científico todo aquellos elementos que el racionalista crítico y el positivista lógico reconocen como metafísicos. Pues de estos elementos - arguye Feyerabend - dependen justamente la posibilidad de superar el conservadurismo conceptual, aumentar el contenido empírico de la ciencia y recuperar el valor descriptivo de las teorías científicas.

Ante la posibilidad de que una teoría seleccione únicamente la evidencia que la confirma, deviniendo así en un dogmatismo, Feyerabend (1965, pp. 150-151) destaca la necesidad de introducir teorías alternativas que proporcionen evidencia nueva o experimentos cruciales capaces de cuestionar o refutar a la teoría imperante. Pero estas teorías no pueden inferirse de la evidencia observacional propia de la teoría vigente. Esta dificultad da al vienés (1981g, p. 36) la oportunidad de reivindicar la necesidad de la metafísica, esta vez entendida como fuente no observacional de las especulaciones que dan origen a las nuevas teorías. El progreso científico reclama que la filosofía no se limite a reflejar o clarificar los desarrollos de la ciencia, sino que desempeñe un papel activo y crítico dentro del mismo quehacer científico construyendo visiones del mundo alternativas a las imperantes (cfr. 1963b, p. 66).

Con su habitual ironía Feyerabend señala la paradoja por la cual el ideal de aumento de contenido - que persigue tanto el popperiano como el positivista - exige adoptar la proliferación teórica y, por ende, ser buenos metafísicos. Según el principio de aumento de contenido una teoría es preferible en cuanto ofrece mayor información que las teorías precedentes. Pues bien, el vienés demuestra que es posible obtener nueva evidencia empírica capaz de refutar una teoría firmemente arraigada en la medida en que se proponen y desarrollan nuevas teorías alternativas. Entonces, el ideal de aumento de contenido empírico sólo se puede asegurar en virtud de una especulación metafísica $^{8}$ que permita instaurar una competencia entre teorías alternativas ( $c f r .1999$ a, p. 99; 2013a, p. 293).

\footnotetext{
${ }^{8}$ Feyerabend concibe la metafísica no como una disciplina autónoma respecto a la ciencia, sino como una dimensión integrada en el cuerpo y la práctica del conocimiento científico, es decir, como las distintas cosmovisiones o metateorías que atraviesan y definen el entero curso del quehacer científico. Para profundizar en las distintas connotaciones y papeles que adquiere en la obra del vienés la metafísica con respecto a la ciencia, véase Gargiulo (2015a).
} 
Este autor también defiende la metafísica en cuanto que por ella la ciencia pueda explicar y dar cuenta del mundo. Para él (1958, pp. 103-104; 1963a, pp. 321-322) las visiones metafísicas constituyen la base del intento de explicar científicamente las propiedades del mundo. Argumenta que si se las excluye la ciencia deviene en un esquematismo predictivo de fenómenos carentes de explicación y sentido. Feyerabend (1981g, p. 22; 1981k, p. 180) sostiene e ilustra concretamente esta tesis con el problema de la interpretación de la física cuántica; insiste en que no habrá progreso en la interpretación de la teoría cuántica hasta que la atención en la sofisticada formulación matemática se dirija hacia los problemas filosóficos fundamentales. ${ }^{9}$

Hasta este punto el vienés procura dar cuenta de cómo aquellos elementos que paradójicamente son descritos por el positivismo lógico o por el racionalismo crítico como acientífico, precientíficos o seudocientíficos constituyen paradójicamente el seno del quehacer científico.

Se podría contemplar la posibilidad de acusar a Feyerabend de cometer aquí una instancia de falacia genética: pues no porque en la metafísica se iniciaron ideas que llegaron a formar parte de la ciencia debe reconocerse el fracaso de la separación entre ciencia y metafísica. $\mathrm{O}$, desde otra perspectiva, no porque en la metafísica se explique la génesis sicológica o accidental de la ciencia se puede decretar la superioridad de aquélla sobre ésta. En pocas palabras, se podría objetar a Feyerabend que no pueda juzgar legítimamente a la ciencia actual en razón de su origen mítico o filosófico.

Tal objeción sería válida si Feyerabend se limitara a defender la metafísica en virtud de que ésta constituye el reservorio imaginativo a partir del cual se originan las teorías científicas. Sin embargo, nuestro filósofo (1963a, pp. 321-322) no defiende la metafísica como un mero dispositivo psicológico que interviene en la invención de nuevos modelos explicativos, tal y como lo hizo Karl Popper. Va más allá, postula la conveniencia metodológica de que la metafísica sea parte de lo que sus interlocutores reconocen como contexto de justificación o quehacer propiamente científico. Sin abandonar nunca el carácter irónico de esta crítica da cuenta de las ventajas metodológicas que se siguen de la integración de la metafísica en la práctica científica, a saber, argumenta que sin ella la ciencia no podría prevenir los dogmatismos que obstaculizan el progreso científico, aumentar su

${ }^{9} \mathrm{Si}$ se quiere ahondar en el planteamiento que Feyerabend hace con respecto al problema realismo-instrumentalismo en el principio de complementariedad de Bohr, véase Gargiulo 2012b. 
contenido empírico y, finalmente, superar el carácter instrumental que caracteriza a muchas de las teorías científicas.

Estas demostraciones de la necesidad metodológica de la metafísica, junto con el abandono de una epistemología normativa, ${ }^{10}$ más sus incursiones en el estudio comprado de las culturas, van acompañadas lógicamente de una nueva valoración del mito y la filosofía y, al mismo tiempo, de una nueva comprensión de la ciencia.

En los años setenta, con la primera formulación de su anarquismo epistemológico, Feyerabend emprende también la tarea de pensar la ciencia desde un horizonte más amplio. En su famoso ensayo Contra el método (1989) — que es el antecesor de las sucesivas ediciones de su Tratado contra el método $\left(1975,1988\right.$ y 1993) — ${ }^{11}$ ya muestra la necesidad de esbozar una explicación más compleja del conocimiento científico que la que ofrece el racionalismo crítico y el positivismo lógico con sus respectivos criterios de demarcación.

${ }^{10}$ A partir de 1965 Feyerabend (1992, p. 17; 1976, pp. 384-385; 1982, pp. 136137; 1981f, p. 235, n. 20; 1995, p. 135) confiesa haber descubierto la pobreza y la ingenuidad de toda filosofía normativa de la ciencia en tanto que mutila o diluye en un par de normas o requisitos metodológicos las vastas posibilidades del movimiento científico. A partir de entonces, desiste de su intento de elaborar una epistemología normativa de la ciencia y, por lo tanto, abandona lo que inicialmente designa como pluralismo metodológico. Su pluralismo metodológico deviene así en un pluralismo teórico, a saber, en un pluralismo entendido ya no como un método sino como una descripción histórica de la práctica científica y como un nuevo modo de entender la ciencia.

Preston (1997a, p. 17) sostiene que a pesar de que a Feyerabend, junto con Kuhn, se le considere como uno de los representantes de la tradición histórica de la filosofía de la ciencia, hasta principios de 1960 aquel perteneció a la tradición normativa, y aún más, en 1990 retornó a una perspectiva normativa. Eric Oberheim (2006, pp. 277-276) corrige o precisa esta tesis de Preston al explicar que Feyerabend no pasó de la defensa de una estricta perspectiva normativa a una aproximación estrictamente descriptiva de la ciencia. En un primer momento, Feyerabend postula desde la historia y la metodología un pluralismo donde los argumentos descriptivos estaban subordinados a los normativos. En un segundo momento, a partir de 1967, presenta las ventajas de su pluralismo, pero está vez subordinando los argumentos normativos a los descriptivos. Para profundizar en esta discusión véanse Farrell 2003, pp. 43-46; Munévar 2006, p. 137; Preston 1997a, pp. 14-17, 137-138; Oberheim y Hoyningen-Huene 2000, p. 367; Oberheim 2006, pp. 85-111, 274-277; Bird 2001, pp. 263-264.

${ }^{11}$ Atenuando la tesis de Hacking (1994) quien sostiene que las publicaciones de su Tratado contra el método constituyen libros diferentes con un mismo título, se puede decir que Feyerabend fue reescribiendo y modificando esta obra de tal modo que fuera acorde con los progresos y avances que hacía con respecto a su comprensión de la ciencia. Esto explicaría los extensos párrafos e incluso los capítulos que en unas ocasiones omite $y$, en otras agrega. 
En las dos primeras ediciones de su Tratado contra el método $(1975,1988)$ Feyerabend objeta los esfuerzos tanto del positivismo lógico como del racionalismo crítico por definir la ciencia a través de un método. Argumenta que las reglas y procedimientos metodológicos son el resultado de atender a la dinámica y al contexto particular de cada investigación. Por lo tanto, es la acción científica lo que define al método y no al revés (1992, pp. xv-xvi). Según Feyerabend, Popper, Lakatos e incluso Kuhn en la medida en que intentan construir una metodología unívoca para la ciencia ofrecen imágenes incompletas e inconsistentes de la ciencia. Para él esto es lo que justifica la necesidad no de una ciencia anárquica, sino de una noción de ciencia que no sea definida por el método. En 1977 bajo el título "Solicitud de un año sabático" Feyerabend ofrece importantes claves para entender su obra. Allí explica que después de la reducción al absurdo de los distintos criterios de demarcación lo que resta es la tarea - caracterizada como un plan a largo plazo - de formular una nueva teoría o modelo de ciencia:

Resultado: ni el contenido, ni el método, ni las reglas de la razón nos autorizan a separar la ciencia de la no ciencia. Toda separación producida es un fenómeno local; se produce bajo ciertas condiciones, entre ciertas partes de la ciencia y ciertas partes de la no ciencia, y no pueden utilizarse para inferir una diferencia esencial entre las cosas separadas.

Plan a largo plazo

Mi plan a largo plazo es construir una teoría del conocimiento que tenga en cuenta esta situación. Esta teoría diferirá en dos aspectos de las teorías del conocimiento al uso:

1) Será una teoría de las ciencias tanto como de las artes (humanidades). En lugar de ver las ciencias y las artes como dos dominios diferentes, presentará a ambos como partes diferentes de una y la misma empresa, del mismo modo que la física y la biología aún son vistas como partes de una y la misma empresa: la ciencia.

2) No contendrá reglas abstractas. Todas las reglas, las de la lógica incluida, quedaran vinculadas a un contexto bien especificado, y dará una razón histórica del contexto y del correspondiente uso de reglas. (Feyerabend 2013c, pp. 302-303)

Ahora bien, en la tercera edición de su Tratado contra el método (1993), Feyerabend da un salto cualitativo: trasciende la discusión 
acerca de la relación que cada teoría establece con su método tal y como se plantea en el marco de una epistemología normativa o descriptiva de la ciencia. Sus críticas y denuncias no tienen como objeto el método en sí más bien la misma noción de ciencia. La cuestión por resolver no es cuál es el método más eficaz sino qué es ciencia.

El vienés denuncia que la filosofía de la ciencia, tal como se desarrolló a lo largo del siglo XX, ha sido incapaz de ofrecer una clara noción de ciencia. Pues si el método es lo que define a la ciencia, y existe una pluralidad de métodos, se debe admitir que existe una infinidad de modos de entender la ciencia. $\mathrm{O}$, en otras palabras, dada la identidad establecida por el racionalismo crítico entre ciencia y método, el anarquismo metodológico obliga a reconocer la ausencia de una definición que explique qué es ciencia (cfr. Feyerabend 2008a, p. 238).

En su autobiografía - a modo de una conclusión que infiere de su extensa crítica a estos modelos teóricos de ciencia- confiesa que "El mundo, el mundo de la ciencia inclusive, es una entidad compleja y dispersa que no puede ser captada por teorías y por reglas sencillas" (1995, p. 135).

Las limitaciones y paradojas que fue descubriendo paulatinamente en las definiciones de ciencia esbozadas por la filosofía de la ciencia lo motivaron a buscar una concepción alternativa de ciencia. De aquí que su obra no puede interpretarse - tal y como lo hacen sus críticos habitualmente - como si ella se restringiera a demostrar las limitaciones de tal o cual principio metodológico, o de un particular criterio de demarcación; o como si la única finalidad que persiguiera fuera subrayar el aspecto histórico o sociológico de la ciencia. La riqueza del pensamiento de nuestro autor radica en haber denunciado el fracaso de los intentos de definir dialécticamente la ciencia a través de una delimitación con lo metafísico. O, dicho de una manera positiva, haber propuesto pensar la ciencia en continuidad con el mito y la filosofía.

En su libro Filosofía natural (2013b) publicado recientemente, ${ }^{12}$ Feyerabend revaloriza el mito y la filosofía como tradiciones cognoscitivas cuyos contenidos y métodos son tan valiosos como los de la

${ }^{12}$ En el epistolario que contiene la comunicación entre Feyerabend y Lakatos (1968-1974/2000), entre los años 1968 y 1974 se menciona el manuscrito de una "Filosofía de la naturaleza", que el primero nunca llegó a publicar —ni siquiera se sabía que lo había escrito-. Entre los años 2007 y 2008, Oberheim, revisando entre los papeles de Feyerabend en el archivo de filosofía de la Universidad de Constanza, halló unas hojas mecanografiadas que, a la postre, resultarían ser aquel proyecto que, sin bien es inacabado - suponía tres tomos-, constituye un verdadero libro. Y de esta manera se publica en alemán y en inglés en 2009 y la traducción al castellano en 2013. 
ciencia. A lo largo de sus distintos capítulos estudia la tradición óptica y teológica del modelo ptolemaico; evalúa, además, la competencia astronómica de Hesíodo, de Jenófanes, de Anaximandro, de Pláton y Aristóteles en y desde sus respectivas cosmologías. Estas investigaciones permiten al vienés sustentar la tesis de que pueden existir alternativas plenamente desarrolladas a una concepción científica del mundo; y que dichas alternativas no pueden evaluarse con los criterios científicos actuales, sino sólo con los propios. Argumenta que en las civilizaciones de preoccidente, el mito hacía vivir de una manera tal que los hombres no "extrañaban" la ciencia. Y, en definitiva, cómo es en esa relación en donde hay que ahondar para poder juzgar "racionalmente" a la racionalidad de la cual la ciencia es el fruto más actual.

En "Solicitud de un año sabático" (2013c) él mismo reconoce que en este sentido da un nuevo paso especulativo en su comprensión de la ciencia. Reflexionando sobre su evolución intelectual, sus trabajos y sus metas como filósofo es importante haber entendido que los mitos y las cosmologías no científicas ofrecen información fáctica sobre el mundo tan detallada como la que otorga la botánica, la biología o la medicina. De aquí que encuentre superflua la consigna popperiana de modificar los mitos de forma que puedan traducir su contenido empírico (2013c, pp. 297-298). Para Feyerabend no existe "una diferencia esencial" (p. 302) entre la ciencia, los mitos y la filosofía.

Cada uno de estos modos de concebir el mundo (ciencia, mito y filosofía) son completos en el sentido de que poseen métodos para alcanzar sus objetivos y para comprobar sus éxitos y fracasos. Cada uno de ellos reivindica una forma de vida que posee un vigoroso núcleo racional —explica Feyerabend (2013b, p. 43; 1992, p. 33; 1982, p. 85 n. 1)-.

Pero el vienés no se limita únicamente a revalorizar el mito como un modo racional de representar el mundo. La noción de mito se le presenta incluso superior al concepto de ciencia, pues le permite entender la ciencia, el arte, la filosofía y la religión como modos alternativos y recíprocamente intercambiables de abordar el mundo. En su Filosofía natural (1970) escribe: "Pero como el mito no admite nada que carezca de sentido [...] puede tener un efecto 'liberador' frente a la ciencia, siendo a veces superior a ésta" (2013b, p. 130). Cuando el mito recoge las transiciones existentes entre esquemas cosmológicos no admite sinsentidos; describe el concepto de realidad que en un determinado periodo histórico influye en el actuar, sentir 
y percibir de los hombres, pero también revela el devenir de los factores psicológicos, sociales y culturales que cambian, en parte, por circunstancias externas y, en parte, como resultado de acciones humanas conscientes:

en el mundo hay transiciones, siendo indiferente que estas transiciones se hallen sin más en el material objetivo o hayan sido introducidas a través de maquinaciones ocultas: después de las maquinaciones, el mundo objetivo observado por el hombre que secretamente lo ordena contiene transiciones, y el mito las recoge (2013b, p. 92).

Según esta interpretación natural del mito los elementos de la realidad, los "hechos" de la conciencia humana no son dados unívocamente. Por el contrario, supone que los hechos más sencillos son modelados conforme a una estructura cosmológica. El mito entonces no es sino la manifestación de un orden determinado que el hombre introduce en el mundo. ${ }^{13}$

La ciencia, a diferencia del mito, se encuentra habitualmente en periodos de transiciones teóricas que constituyen auténticos problemas de sentido. $\mathrm{Y}$ esto es lo que Feyerabend se propuso mostrar con su doctrina de la inconmensurabilidad. A saber, en las revoluciones científicas la ciencia — entendida desde los mismos principios y cánones del positivismo lógico y racionalismo crítico - no dispone de elementos para poder determinar qué es lo racional y lo objetivo. En una transición teórica existe una sustitución de ontología y un correspondiente cambio en el significado de los términos observacionales y en el modo de seleccionar y disponer los hechos empíricos y los métodos. Entonces, ninguno de estos elementos (los hechos empíricos, los términos observacionales o los métodos) puede constituir el criterio universal y objetivo en función del cual se determine la superioridad de una de las teorías sobre sus rivales.

Analizando desde otro ángulo el problema de la inconmensurabilidad se puede decir que en las transiciones teóricas es imposible poder distinguir desde el interior de una teoría científica los hechos de las teorías, el objeto real del objeto teórico, los elementos objetivos de los subjetivos, lo empírico de lo metafísico, lo racional de lo que parece ser irracional. Esto se debe a que cada teoría científica, en función de la ontología o visión del mundo que la anima, establece un criterio

${ }^{13}$ Feyerabend (2013b, pp. 90-91) destaca que este orden que se presenta de una manera indirecta está en el mundo, y con esta afirmación se aleja así de la teoría estructuralista de Levi-Strauss según la cual el orden representado no es de orden natural sino lógico, es decir, existe únicamente en la mente de quien lo observa. 
de demarcación particular y arbitrario entre estas realidades. De aquí que ninguno de estos elementos puede constituir el criterio en virtud del cual se determine la racionalidad u objetividad de una teoría sobre otra. Y he aquí el absurdo o la paradoja que el positivismo lógico y el racionalismo crítico deben admitir: lo que constituye el seno de progreso científico es algo que éstos sólo pueden catalogar como irracionalidad y anarquismo.

No sólo el mito, también el arte constituye para Feyerabend un medio más apto para expresar el devenir del quehacer científico y de las culturas en general. En su artículo "Let's Make More Movies" (1999c, pp. 198-199) presenta el arte escénico y el cine como capaces de representar la unidad de los elementos antagónicos que interactúan en un momento histórico, esto es, las teorías, las lecturas, las imágenes, las emociones, las instituciones y el estilo de vida que deviene y se transforma como resultado de tales interacciones. La primera versión de esta tesis se encuentra en "On the Improvement of the Sciences and the Arts, and the Possible Identity of the Two" (1967, p. 411) donde argumenta que por el bien de la cultura occidental, no debería haberse abierto el abismo entre las ciencias y las artes; e invita a que la ciencia se reapropie del método de múltiple representación característico del arte moderno. Un año más tarde publica "Outline of Pluralistic Theory of Knowledge and Action" (1999b, p. 105) donde asegura que tanto la ciencia como la filosofía deben aprender de la forma en que el arte contemporáneo se resiste a manifestar la realidad en conformidad con un único punto de vista. La ciencia debe imitar el pluralismo y la libertad de la creación artística. En su Filosofía natural (2013b, p. 134) escribe que la ciencia, en lugar de autoconsiderarse la única vía para conocer objetivamente el mundo, es decir, como si ella reflejara en sí misma exclusiva y correctamente los rasgos generales del mundo, debe imitar al mito y al arte en cuanto ambos manifiestan la contingencia de todo modo de representar y vivenciar el mundo.

Esta teoría acerca de la estructura y función del mito le ofrece al vienés las claves para un nuevo modo de comprender la ciencia, el arte y la filosofía: todas ellas deben ser entendidas en un sentido mitológico en cuanto que todas ellas recojan las transiciones de sentido que expresa el mito.

El mito, la filosofía, el arte y la ciencia no son mas que manifestaciones contingentes de un mundo abundante. Entonces debería abandonarse todo intento de establecer una jerarquización entre estos tipos de saberes (Feyerabend 2013b, p. 89). No sólo porque éstas 
constituyen vías alternativas para comprender el mundo, sino porque la continua comunicación que existe entre ellas conforma un único devenir histórico:

Las tres formas de vida a que se refiere - mito, filosofía y ciencia - ni pueden separarse nítidamente, ni se suceden siempre por este orden. El mito anticipa la ciencia, y la ciencia tiene rasgos mitológicos; filosofía, ciencia y mito ora conviven pacíficamente, ora se disputan el derecho a existir; "supersticiones" y "prejuicios" los encontramos por doquier. (2013b, p. 37)

Los límites entre la ciencia, el mito y la filosofía quedan desdibujados. La ciencia entendida como la cultura occidental evoluciona y fluctúa a lo largo de la historia interactuando con diversos mitos y cosmovisiones del mundo. La ciencia, el mito y la filosofía no constituyen culturas cerradas, por el contrario, se suceden en una continua y recíproca interacción conformando un único proceso histórico a partir del cual se configura la cultura occidental. En su Filosofía natural (2013b) Feyerabend procura demostrar la continuidad existente entre los mitos y las distinciones filosóficas que conforman la visión científica del mundo. En el capítulo cuatro describe cómo la experiencia y el lenguaje mítico de Homero deviene en el mundo de los filósofos. En el capítulo cinco argumenta que los presupuestos metafísicos de la ciencia occidental están explícitamente formulados tanto en la visión del mundo como sustancia de Parménides, como en la crítica de Jenófanes al mito con su consecuente distinción entre lo real y lo aparente. En el capítulo seis explica no sólo cómo se desarrollaron dichos presupuestos sino como las teorías físicas, principalmente la de David Bohm, marcan el punto de partida de una nueva ciencia filosófica-mitológica. Este acontecimiento de mitos y cosmovisiones metafísicas atraviesa la lectura que hace Feyerabend de la historia de la ciencia. Al discurso de Aquiles, la filosofía de Parmenides, la crítica de Jenófanes a los dioses mitológicos, la filosofía de Descartes, el empirismo de Galileo, el mecanicismo de Newton y un largo, etc., los expone el vienés como hijos de una misma tradición que engendra a la ciencia moderna.

En contra de los filósofos de la ciencia que buscan definir la actividad científica, mediante cánones abstractos, Feyerabend la presenta como una tradición que se manifiesta como históricamente heterogénea. La ciencia es, en sí misma, una tradición histórica, y ante la pregunta por la estructura propia de esta tradición y por los elementos que la distinguen de las demás tradiciones, el vienés responde que la 
ciencia posee una estructura que se define en función de las múltiples tradiciones mitológicas y filosóficas que la atraviesan históricamente.

\section{La ciencia como una tradición más entre otras}

En este segundo punto procuraré mostrar que Feyerabend no sólo postula el relativismo como una de las consecuencias absurdas que se sigue del racionalismo, sino que propone positivamente una forma de relativismo, pues éste se le presenta inicialmente como condición de una práctica científica más conciente y respetuosa de las condiciones que exige una convivencia democrática con las demás tradiciones. En pocas palabras, el relativismo se le presenta como ineludible en la tarea de construir una ciencia más humana.

Como resultado de sus denuncias en contra de los intentos del positivismo lógico y del racionalismo crítico por establecer un criterio de demarcación, Feyerabend termina por postular no sólo la continuidad entre el mito, el arte, la filosofía y la ciencia, sino también la igualdad de derecho que debe existir entre ellas. Es decir, ante la impotencia del positivismo y del racionalismo por ofrecer un fundamento que garantice la superioridad de la ciencia occidental sobre las demás tradiciones, nuestro filósofo (1999d, pp. 204-205; 1982, pp. 12, 27, $99,161)$ termina defendiendo positiva y explícitamente la razonabilidad del relativismo y se define a sí mismo como un relativista en el antiguo sentido de Protágoras. ${ }^{14}$

Puntualmente, Feyerabend, en La ciencia en una sociedad libre (1982, pp. 114-117), cuestiona la supuesta superioridad de la ciencia cuando muestra que no existe todavía una instancia que la justifique racionalmente. Si se pretende fundar su superioridad en el método, el vienés muestra que no existe tal unidad o universalidad en el método. Si se justifica su superioridad en virtud de sus resultados, nuestro filósofo admite las prodigiosas contribuciones de la ciencia, pero alega que no es posible saber si otras tradiciones podrían haber ofrecido mejores resultados; resultados que se miden en función de la vida digna que ofrecen al ser humano. Entonces, concluye, fueron motivos meramente políticos y propagandísticos los que causaron la hegemonía de la ciencia. Por lo tanto, la ciencia debe considerarse una tradición particular entre otras.

La racionalidad científica no constituye un metacriterio según el cual se pueda juzgar objetivamente a las demás tradiciones, pues la racionalidad científica en sí misma no es más que una tradición

\footnotetext{
${ }^{14}$ Para estudiar las distintas posturas que Feyerabend sostiene con respecto al relativismo, véase Gargiulo 2015d y 2016a.
} 
coexistente con otras formas de comprender el mundo. Ninguna tradición posee una superioridad intrínseca sobre sus rivales. Sólo se podría adjudicar superioridad a una tradición en particular si arbitrariamente se opta por sus pautas de evaluación y, a continuación, se aplican tales criterios a los estilos alternativos. Las tradiciones —explica Feyerabend (1999d, pp. 202-203; 1982, pp. 20-21, 27 y 93) — no son ni buenas ni malas, simplemente son. Clasificarlas como verdaderas o falsas supone proyectar sobre ellas los valores o puntos de vista de otras tradiciones. La apariencia de objetividad que puede presentar un juicio sobre una tradición se debe a que en él no se hace referencia alguna a las idiosincrasias personales del que juzga. ${ }^{15}$

Esta ausencia de razones para preferir la ciencia y el racionalismo a otras tradiciones parecería justificar, en parte, la posición relativista que Feyerabend sostiene con respecto a la ciencia desde mediados de la década de los setenta hasta fines de la década de los ochenta. Éstos son los motivos que lo conducen a entender la ciencia como una tradición más, es decir, como una de las tantas formas existentes de ver el mundo.

Nuestro epistemólogo señala el peligro que existe de que la ciencia se convierta en una ideología, en el sentido que inhiba el desarrollo de las demás cosmovisiones no científicas. En un momento histórico la ciencia pudo haber representado la oposición a un pensamiento dogmático - explica Feyerabend-. Pero en la medida en que ésta goza en la sociedad de una prioridad ex profeso puede devenir en una ideología que es impuesta por la fuerza. De aquí la necesidad de complementar la separación entre iglesia y estado con la separación entre estado y ciencia:

Así pues, la ciencia es mucho más semejante al mito de lo que cualquier filosofía científica está dispuesta a reconocer. La ciencia constituye una de las muchas formas de pensamiento desarrolladas por el hombre, pero no necesariamente la mejor. Es una forma de pensamiento conspicua, estrepitosa e insolente, pero sólo intrínsecamente superior a las demás para aquellos que ya han decidido en favor de cierta ideología, o que la han aceptado sin haber examinado sus ventajas y sus límites. Y puesto que la aceptación y rechazo de ideologías debería dejarse en manos del individuo, resulta que la separación de iglesia y estado debe complementarse con la separación de estado y ciencia; la institución religiosa

${ }^{15}$ Feyerabend (1999e; pp. 183-184; 1976, p. 387; 1999f, pp. 212-213, 215; 1981d, pp. 139-143; 1981f, p. 246; 2000, pp. 79-80) reconoce a Stuart Mill - particularmente por su ensayo De la libertad (1879) - como uno de los exponentes más importantes de esta tesis. 
más reciente, más agresiva y más dogmática. Semejante separación quizá sea nuestra única oportunidad de conseguir una humanidad que somos capaces de realizar, pero que nunca hemos realizado plenamente. (Feyerabend 1992, p. 289)

Feyerabend juzga el racionalismo humanista de Popper como una versión desvirtuada de la filosofía de Mill. En La sociedad abierta y sus enemigos (1945) lo acusa de ofrecer una estructura formal que garantiza únicamente la primacía de la ciencia sobre las demás tradiciones sin atender la felicidad y la libertad individual, rasgo característico del liberalismo de Mill (Feyerabend 1992, p. 32, n. 35; 1999d, p. 218; 1982, pp. 3-4, 29, 89-90, 117, 124, 149; 1981e, p. 31). La consecuencia que esta forma de proceder tiene sobre la existencia humana no es sino la obstaculización del libre desarrollo de la humanidad y de la vida en democracia (1982, pp. 158-159).

Feyerabend denuncia el proceder de la escuela popperiana como un comportamiento diametralmente inverso al de Mill. Su objetivo primario no es hacer de la ciencia una empresa más humana, sino elaborar un método. Como respuesta a las cuestiones metodológicas y epistemológicas que plantea el problema de la inducción de Hume, Popper generaliza una metodología o actitud crítica que debe regir no sólo a la ciencia sino a la política y conducta humana en general (Feyerabend 1992, p. 161; 1982, p. 141; 2005, pp. 64-65; 1999h, pp. 107-108). Ahora bien, dicho método se limita a ofrecer un modelo matemáticamente descriptible y empíricamente contrastable que nada dice acerca de la relación del hombre con respecto a la naturaleza. El vienés escribe que en Popper "las consideraciones humanistas están reducidas al mínimo" (1992, p. 176).

En este sentido, sería más apropiado decir que el humanismo del vienés se inscribe en la filosofía de Mill $^{16}$ y relativizar las afirmaciones de Oberheim (2006, pp. 93-94), quien asegura que a pesar de que Feyerabend adopta una actitud crítica con respecto al racionalismo crítico, no deja de adoptar la actitud normativa de la ética — propia de la tradición popperiana - para juzgar la ciencia.

Feyerabend propone una sociedad donde cada ciudadano juzgue la ciencia y las demás tradiciones según el estilo de vida que quiere llevar (1999e, pp. 190-191; 1982, p. 100; 1993, pp. 182-184; 1999f, p. $215 ; 2005$, pp. 66, 78-80). La convivencia pacífica de las distintas tradiciones y el progreso científico constituyen para él algo positivo

\footnotetext{
${ }^{16}$ Para un estudio crítico sobre el humanismo de Feyerabend como heredero de la filosofía de Mill véase Lloyd 2000, pp. 122-123; Downes 2002, pp. 163-164.
} 
en la medida en que son puestas al servicio del hombre y de la felicidad individual de cada uno de los ciudadanos. ${ }^{17}$

Su concepción de la ciencia como una tradición más entre otras no sólo supone abogar por una forma de relativismo, sino que supone, sobre todo, la búsqueda de una ciencia más humana. En este sentido su relativismo puede entenderse como la defensa de una ciencia más atenta y cercana a la vida del hombre y del ciudadano:

Tampoco deberíamos contentarnos con aumentar el contenido de verdad, el contenido empírico o cualquier otra cualidad. Comparadas con una vida plena y feliz estas cosas cuentan muy poco. Necesitamos una filosofía que dé a los hombres el poder y la motivación para hacer una ciencia más culta, en lugar de hacer una ciencia súper eficaz, súper verdadera, por un lado, pero tan bárbara, por otro, que degrada al hombre. Una filosofía así debe mostrar y probar todas las consecuencias de una existencia exigente, incluidas aquellas que no se pueden expresar por medio de palabras. Por eso no debe haber ninguna línea de demarcación entre filosofía y el resto de la vida humana. (Feyerabend 1993, p. 27)

Atendiendo a los escritos de Feyerabend de esos años, Gabriel Zanotti resume su concepción de ciencia en una noción dialógica de ciencia:

Ser partidario de las críticas de Feyerabend [...] es pasar, sencillamente, de la razón positivista a la razón dialógica, que incorpora en su seno la comprensión, la comunicación y la convivencia pacífica con todo aquello que no es esa ciencia. [...] La "nueva" ilustración es ya modernidad más que ilustración, en la medida en que incorpora una razón dialógica que se aleja del ideal positivista de una ciencia "gobernante". De ese modo podría decirse que sí, que efectivamente la modernidad, en la ciencia, es un ideal no alcanzado, y que tal vez pudiera darse en un futuro cuando la razón occidental, en todos los ámbitos, pero sobre todo en el científico, incorpore el diálogo, la distinción de estado y ciencia y la consiguiente convivencia pacífica con otras formas de concebir la racionalidad. (2005, p. 235)

Esta caracterización de su obra como la formulación de una ciencia no dogmática es correcta en la medida en que se la conciba como una respuesta dialéctica al racionalismo crítico. Pero es incompleta si se observa que paralelamente a su crítica del racionalismo crítico, Feyerabend en su Filosofía natural (2013b) — tal como se expuso

\footnotetext{
${ }^{17}$ Para estudiar la preocupación de Feyerabend por hacer de la ciencia una empresa más humana véase Gargiulo 2012a y 2016b.
} 
en el punto anterior- se propone formular un nuevo modo de comprender la ciencia como una multiplicidad de tradiciones mitológicas y filosóficas:

La simpatía con esta naturaleza, la comprensión intuitiva de la vida múltiple que ella encierra y el pleno desarrollo de la propia personalidad son partes esenciales de la nueva ciencia filosófico-mitológica que, aunque aún vagamente, hoy se dibuja en el horizonte. Una de las tareas de la presente obra es la de clarificar los antecedentes históricos — descubrimientos y errores - de esta ciencia y así adelantar su nacimiento. (2013b, p. 282)

La ciencia no dialoga simplemente con el mito, la filosofía o cualquier otra tradición de pensamiento, sino que ella misma, al entender del vienés, es mítica y filosófica.

\section{La ciencia como manifestación de un Ser abundante}

Ahora bien, no se haría una justa valoración de la obra de Feyerabend si dejásemos de considerar que al final de su vida tuvo un acercamiento a una metafísica capaz de trascender su antigua posición relativista. En esta última sección, expondré cómo de pasar de una forma extrema de relativismo a un relativismo cosmológico manifiesta no sólo su preocupación por ofrecer un fundamento ontológico para la ciencia y la cultura, sino también para concretar una nueva forma más humana de hacer ciencia. En su metafísica de la abundancia el vienés invita a pensar en una ciencia que sea más consciente del estilo de vida y de los valores humanos que propone con sus progresos. Invita a juzgar el valor intrínseco de la ciencia por el modo de vivir el mundo que propone a sus miembros.

A finales del año 1980 y a comienzos de 1990 Feyerabend busca atemperar su posición relativista. En una carta con fecha del 20 de julio de 1989, Feyerabend le responde a Couvalis $(1999$, p. 49, n. 1) que la acusación de relativista que le hace es irrelevante dado que ya no es un relativista. Pero sosteniendo quizá una postura aparentemente ambigua en "Concluding Unphilosophical Conversation" (1991c, p. 507) afirma: "Confieso ser en algunos sentidos un ferviente relativista, pero ciertamente no soy un relativista en otros." A su amigo Munévar ${ }^{18}$

\footnotetext{
${ }^{18}$ Munévar (1991b, pp. 191-197) le reconoció a Feyerabend que estaba en lo correcto cuando sostenía que los racionalistas no ofrecen buenos argumentos para dar cuenta de la superioridad de la ciencia por sobre otras tradiciones. No obstante, alega que los argumentos que desarrolla en contra de la excelencia de la ciencia
} 
le confiesa no sólo su desencanto con respecto al relativismo que hasta entonces sostuvo, sino además el consecuente abandono de su consideración de la ciencia como una forma de conocimiento entre otras:

Bueno, lee mi próximo libro, La conquista de la abundancia donde explico todo en detalle. En cualquier caso - yo ahora estoy de acuerdo con Munévar en que la ciencia debe conservar su papel excepcional en Occidente pues ella se adapta mejor a nuestra situación actual-: Occidente está cubierto de los excrementos de la ciencia luego, naturalmente, necesita científicos para limpiarlo. Sin embargo, me gustaría añadir que hay otras maneras de vivir en este mundo. La gente ha actuado sobre el mundo de muchas maneras diferentes, en parte físicamente, interfiriendo físicamente en él, en parte conceptualmente, mediante la elaboración de lenguajes y haciendo inferencias a partir de ellos. Algunas de estas acciones encontraron una respuesta, otros nunca despegaron del suelo. Para mí esto sugiere que hay una realidad y que es más flexible de lo que la mayoría de los objetivistas supone. Son posibles distintos modos de vida y de conocimiento porque la realidad los permite e incluso los favorece, y no porque la "verdad" y la "realidad" sean nociones relativas (Feyerabend 1991c, p. 516, TN.) ${ }^{19}$

En Diálogos sobre el conocimiento Feyerabend (1991b, pp. 111-114, 121-123) explica que tanto en su Tratado contra el método como en La ciencia en una sociedad libre sostuvo que la ciencia era una tradición de conocimiento entre otras. Esta tesis implicaba dos cosas: primero, que la realidad permite enfoques distintos, entre ellos, el científico; y segundo, que el conocimiento (la verdad) es una noción relativa. Confiesa haberse retractado, puntualmente en 1987, de esta primera forma de relativismo para formular una nueva forma de relativismo que reconoce como un relativismo cosmológico. Tanto en

fracasan porque dejan abierta la posibilidad de que la ciencia se sitúe en una posición prominente en razón de su metodología y de sus resultados. Aunque esta prominencia - explica Munévar- no es inherente, sino que es el resultado de la relación con las exigencias actuales de la investigación y con las necesidades de las sociedades modernas. En este sentido, la sociedad también tendría el derecho de favorecer la ideología científica si ofrece una forma de vida más deseable que la que prometen otras tradiciones. Ahora, nada de lo anterior — alega Munévar - demuestra que una sociedad libre debe elegir necesariamente el camino de la ciencia. Pues bien, en este giro de un relativismo radical a un relativismo cosmológico Feyerabend parece considerar el peso de los argumentos de Munévar.

${ }^{19}$ Quizá estas fueron las razones por las cuales Feyerabend se rehusaba a la idea de reeditar La ciencia en una sociedad libre tal como cuenta su viuda Grazia Borrini (1999, p. xi). 
Adiós a la razón (2005) como en "Postscript on Relativism" (2008b, pp. 270-271) el vienés cuenta haber abogado por un relativismo cosmológico como parte de una ciencia no dogmática que se caracteriza por la defensa de la primera tesis y por el rechazo de la segunda (cfr. Feyerabend 1991c, p. 519). ${ }^{20}$

Podríamos sintetizar su relativismo cosmológico con la siguiente tesis: la realidad permite enfoques distintos, pero esto no implica que la realidad o la verdad sea una noción relativa.

Para el vienés $(2005$, pp. 161, 162) a las distintas formas de explicación o representación que ofrecen las culturas se les concibe como manifestaciones parciales de un Ser abundante. Las distintas culturas constituyen aproximaciones a un Ser o mundo cuya complejidad y abundancia excede sus marcos de comprensión. De aquí que entienda a las estructuras de comprensión que ofrecen las culturas como una expresión histórica de un mundo cuya infinidad es en sí misma inasible. Entonces la ciencia deja de ser una única vía de conocimiento objetivo del mundo para convertirse en una de las expresiones contingentes de un mundo que la trasciende. De este modo, Feyerabend (2008b, pp. 271-272) procura destacar el carácter histórico y contextual de las tradiciones y, al mismo tiempo, evitar las consecuencias historicistas o relativistas que se siguen, a su entender, de los estudios de Kuhn.

Con el fin de superar su antiguo relativismo Feyerabend alcanza una noción de Ser o mundo que parece ser el fundamento último que define el valor intrínseco de las teorías o cosmovisiones. Es difícil caracterizar positivamente, o decir qué es, ese fundamento. Lo fue para él, y por esa razón utiliza diversos términos: Dios, Ser, mundo, materia, realidad. La tarea crítica que ha llevado a Feyerabend hasta ese ser determina mucho más claramente lo que no es que lo que es positivamente. Empero, se puede decir con seguridad que sería traicionar profundamente el íntimo movimiento de su pensamiento si no se afirmara que el abandono de su anterior relativismo y su reformulación de un relativismo cosmológico es dependiente de esta noción de Ser postulada en su metafísica de la abundancia.

El filósofo vienés (1999g, p. 173) opone al relativismo la noción de resistencia del Ser. Allí explica que esta resistencia o aprobación del

\footnotetext{
${ }^{20}$ Harris (1992) no parece haber tomado en cuenta estos giros en la obra de Feyerabend, pues utilizando citas que sacó de contexto presenta su pensamiento en el marco de un relativismo radical. Preston (1997b, pp. 424 y 427; 2000, pp. 94-96), por otro lado, obviando las confesiones y las distintas argumentaciones por las cuales el vienés busca superar su antiguo relativismo, asegura que en sus últimas obras éste evolucionó hacia un relativismo tan extremo como el cosntructivismo social.
} 
Ser es justamente lo que no tienen en cuenta los constructivistas o relativistas. Para un relativista o constructivista toda proyección es válida. Las culturas no son más que el producto de un contexto histórico determinado. Para él, en cambio, "No todas las proyecciones son exitosas" (1999g, p. 168) pues la naturaleza o el Ser "no es algo amorfo a lo que se le pueda dar cualquier forma. El Ser resiste y mediante su resistencia revela sus propiedades y leyes" (1999g, p. 280). Para evitar que su obra tardía sea inscripta en los límites de un constructivismo social, escribe:

otros importan el término "relativismo" y me lo aplican. Pero todavía les puedo corregir de la siguiente manera.

Para empezar, no todas las formas de abordar la "realidad" tienen éxito. Como ocurre con las mutaciones inadaptadas, algunos enfoques sobreviven durante un tiempo - sus agentes sufren, muchos muereny, entonces, desaparecen. Así, la mera existencia de una sociedad con ciertos modos de conducta y ciertos criterios para juzgar lo que se ha conseguido no es suficiente para establecer una realidad manifiesta, también hace falta que Dios, el Ser, o la Realidad Básica, reaccione de un modo positivo (1999g, pp. 253-254).

A través de este lenguaje metafísico y antropomórfico acerca de la aprobación o resistencia del Ser Feyerabend pretende expresar y determinar la calidad o no de vida que proponen las culturas a sus miembros. El Ser o la naturaleza aprueba las culturas en la medida en que ellas proporcionan a sus miembros una vida buena y plena; pero se resiste a aquellas que no la ofrecen. Su metafísica revela cómo las culturas con sus consecuentes estilos de vida participan de la complejidad y abundancia del mundo (1999g, p. 232). ${ }^{21}$

${ }^{21}$ Farrell (2003, pp. 233-236) contempla la posibilidad de que se le señale a Feyerabend una aparente tensión entre su crítica a los sistemas abstractos de pensamiento y su simultánea propuesta de un pluralismo teórico. Pues mientras denuncia que dichos sistemas son incapaces de captar la abundancia y la complejidad de la existencia, alienta una proliferación que exige justamente la construcción de nuevas visiones del mundo que por su misma naturaleza son de un carácter abstracto y comprensivo. Si Feyerabend sostiene que no hay leyes abstractas y universalmente válidas subyacentes a la existencia, entonces no puede alentar la construcción de visiones del mundo que incorporan justamente tales leyes. Por lo que parecería que la obra de Feyerabend se refutaría a sí misma a través de esta contradicción interna.

No obstante, la razón de ser de esta crítica estriba en ignorar que Feyerabend es altamente crítico no de las visiones del mundo u ontologías en cuanto tales, sino del carácter reductivo de muchas de éstas, es decir, las ataca en cuanto se erigen en sistemas que buscan la unidad a expensas de excluir amplios aspectos de la realidad. Tal es el caso del racionalismo científico, que denuncia el vienés, el cual desde una 
Para Feyerabend el valor humano se erige como el criterio de éxito de las culturas. Lo humano — entendiendo por tal el contenido vivencial de una teoría o cultura - constituye uno de los valores epistémicos primarios por el cual el vienés evalúa y crítica la supuesta superioridad de la ciencia frente a otras tradiciones de pensamiento (1991b, pp. 87-89, 123-125; 1999g, pp. 187-188, 232; 1999h, pp. 4143). En esta dirección asegura que el progreso científico - que particularmente parece haber alterado el equilibrio del hombre con la naturaleza que se había alcanzado en épocas anteriores- debe ser juzgado por las consecuencias que se siguen de él para la existencia humana. ${ }^{22}$

En el manuscrito inconcluso Conquista de abundancia (1994) Feyerabend explica que las entidades y teorías científicas deben juzgarse como reales o no según si el mundo a que dan lugar es placentero o no para vivir. Define lo real como "aquello que tiene un papel importante en el tipo de vida que uno quiere vivir" (1999g, p. 292. Cfr. 1981, pp. 13-14; 1991b, p. 53, 87-89, 123-125; 1999g, p. 33, 96, 255). De aquí que exija que los resultados científicos sean beneficiosos para el individuo y la sociedad antes de convertirlos en medida de la realidad. Puesto que "la ciencia humana se debe adaptar a los requerimientos de una vida plena y equilibrada" (1999g, p. 255).

ontología reduccionista pretende definir lo objetivo instaurando falsas dialécticas entre lo real y lo aparente, entre sujeto y objeto, entre racionalismo y relativismo.

Para Feyerabend todos los aspectos de la existencia son igualmente reales, ninguna parte circunscripta de la existencia es metafísicamente superior a las demás. De aquí que al final de su vida subraye que a la hora de descubrir la abundancia de lo real las humanidades, la religión o las tradiciones antiguas sean tan buenas candidatas como la ciencia.

Nuestro filósofo al afirmar que "toda cultura es potencialmente todas las culturas" (2003, p. 165), abre la posibilidad de que exista una única cultura en el mundo, aunque sin dejar de ser consecuente con su pluralismo no reductivo. Pues esta cultura extensa no sería el resultado de la dominación de una cultura sobre las demás sino, más bien, la consecuencia de un debate abierto, de la interacción y de la evolución de distintas culturas. Esta nueva cultura no se identificaría con ninguna visión del mundo particular, sería pluralista en contenido y, por lo tanto, capaz de describir todos los aspectos de la existencia mejor que cualquier otra visión del mundo.

${ }^{22}$ Erigir los valores espirituales o el conferimiento de sentido no es abogar por la irracionalidad o la mera subjetividad como Preston sostiene (1997a, p. 210; 2000, pp. 90-91). Valorar la humanidad de la ciencia por la vida buena plena que ofrece una tradición, excede evidentemente los criterios de veracidad o validez de cualquier racionalista; y es que Feyerabend parece aquí entrever la identidad metafísica entre verdad y bien, entre ciencia y felicidad que fue olvidada y abandonada paulatinamente en las nociones modernas de método, ciencia y objetividad. 
Lo que nuestro autor busca en su metafísica de la abundancia no sólo es relativizar los logros de la ciencia comparándolos con los de las tradiciones míticas o filosóficas. Más bien lo que pretende es una mejor comprensión de la ciencia y emprender una ciencia más consciente de los supuestos que animan su evolución histórica y capaz de dar cuenta del estilo de vida y de los valores humanos que propone con sus progresos. Feyerabend formula una teoría del conocimiento y un criterio de realidad que acerca la ciencia a las vivencias humanas. Es decir, procura pensar una ciencia que represente un bien para el hombre y que esté a su servicio y no a la inversa.

La realidad debe juzgarse de acuerdo con la experiencia y el sentido común de los hombres. Por lo que el uso e interpretación de los resultados científicos también es una cuestión política que tiene que ver con la vida de la gente tal y como ésta se expresa en sus experiencias diversas ( $c f r$. Feyerabend $1999 \mathrm{~g}$, p. 258).

En cuanto que el vienés hace depender lo real de la tradición que el hombre elija, la ciencia queda supeditada a una decisión ética. Por ética, Feyerabend (1999g) entiende aquella decisión individual de asumir un determinado tipo de vida y, por lo tanto, un modo particular de entender y vivir el mundo. En este sentido escribe que la ética debe convertirse en "juez público" (p. 291 de la ciencia. "[L]a ética (en el sentido general de una disciplina que guía nuestras elecciones entre formas de vida) afecta a la ontología" (2003, p. 70). Feyerabend recoge y expone dicha conclusión en su artículo "La ética como medida de la verdad científica" (1992):

Una primera y bastante inmediata consecuencia [del principio de Aristóteles] es que la línea divisoria entre la realidad y la apariencia no puede establecerse mediante la investigación científica porque contiene un componente normativo o, si lo prefieren, "existencial".

Esto explica, en segundo lugar, por qué tantos procesos distintos (visiones, experiencia inmediata, sueños y fantasías religiosas) han sido declaradas reales y por qué las discusiones en torno a la realidad son tan acaloradas. Después de todo, se trata de debates sobre el modo correcto de vivir o, en ámbitos más restringidos sobre el modo correcto de hacer investigación. Llegan a un acuerdo sobre el peso que debemos dar a la razón, la experiencia, la emoción, la fe, la fascinación y otros entes que en algunas teorías están estrictamente separados, mientras que en otras aparecen mezclados (Feyerabend 2003, p. 80).

Toda teoría, toda tradición o cultura posee una noción metafísica de realidad que trasciende el conjunto de datos científicos que disponen 
a su favor. Estas nociones metafísicas de realidad se definen en virtud de un componente ético normativo que en la ciencia o en la visión científica del mundo también se ha planteado, aunque subrepticiamente y sin discusión. Feyerabend (2003) propone iniciar un debate sobre las implicancias éticas y humanas de las tradiciones y culturas introduciendo nuevas maneras de definir lo real o de discriminar metafísicamente lo real con respecto a lo aparente. De este modo, la ética juzga abiertamente el contenido ético implícito en sus distintos criterios de realidad. "Podemos decir que la ética, habiendo sido una vez la medida secreta de la verdad científica, puede ahora convertirse abiertamente en su juez" (p. 71).

La ciencia debe someterse a la ética y no a la inversa. Sin embargo, Feyerabend se opone a todo intento de concebir la ética como un sistema a priori de normas universales inferidas de la ciencia. Ésta no puede ser entendida como la universalización o explicitación de los valores implícitos en la visión científica del mundo. No se puede juzgar una cultura o tradición por lo ideales propios del racionalismo cientificista. Por ejemplo, el nivel de vida que las tradiciones ofrecen a sus miembros no puede ser evaluado en función del producto nacional bruto, de la esperanza de vida o del nivel de alfabetización. Es, decir, no se puede medir su calidad de vida desde los valores de la cultura occidental. En este sentido afirma que no se puede argumentar desde la realidad científica hacia la ética y los derechos humanos:

Según Fang, argumentamos desde la realidad científica hacia la ética y los derechos humanos. Éste es un movimiento peligroso. Usa normas, pero las esconde tras enunciados factuales, elimina nuestras elecciones e impone leyes en lugar de dejar que maduren a partir de la vida de sus supuestos beneficiarios. Yo sugiero que argumentemos al revés, desde el tipo de vida "subjetivo", "irracional" e idiosincrásico que somos, en sintonía con lo que va a ser considerado real. La inversión tiene muchas ventajas. Está de acuerdo con los derechos humanos. Nos hace tomar conciencia del hecho de que la "realidad" de Fang es el resultado de una elección y puede ser modificada: no estamos obligados a mantenernos fieles al "progreso" y a la "universalidad". (2003, p. 74)

Feyerabend invierte el habitual cuestionamiento cientificista sobre las implicancias éticas de la ciencia. A las culturas no se les puede juzgar desde el racionalismo occidental. Por el contrario, éstas deben ser evaluadas desde interrogantes éticos comunes a toda la naturaleza humana tales como "¿son realmente meros sueños, o hay en ellas 
felicidad, perspicacia, comprensión, afecto y un crecimiento gradual desde la infancia, pasando por la adolescencia, hasta la madurez y vejez? ¿Hay una actitud generosa hacia los demás más allá de las intenciones?" (2003, p. 71). Así lo real, se establece conforme a aquello que proporciona a los hombres una vida feliz y plena en tanto despliega las facultades humanas.

Esto no supone, por parte de Feyerabend, un desprecio de la ciencia, sino el deseo de que ésta recupere su dimensión humana supeditándose al juicio, a la libertad y a la dignidad del hombre. Su esposa Gracia Borrini (1999, p. 14) caracteriza el modelo de ciencia que Feyerabend persigue en sus últimas obras como aquel que no reduce la riqueza y complejidad del ser y que sostiene pero nunca degrada la vida que tiene sentido para el hombre.

Entendemos que Feyerabend no habría estado de acuerdo, en absoluto, en que se interpretara su metafísica de la abundancia como un metarrelato, si por metarrelato se entiende un discurso lógico que resuelve de forma abstracta y definitiva el problema de la inconmensurabilidad y, por ende, el de la determinación de la supremacía de una tradición sobre las otras. Pues esto implicaría la formulación de una nueva forma de racionalismo el cual constituyó uno de los blancos más importantes de sus críticas.

Tampoco es válido afirmar que tal metafísica de la abundancia queda limitada a constatar históricamente una pluralidad de discursos, pues con ella el vienés intenta inaugurar una manera más humana de hacer ciencia y de dar cuenta del progreso científico; a saber, una hermenéutica que tiene como fin juzgar las culturas, entre ellas a la misma ciencia, por su contenido humano y existencial. De esta manera, busca restablecer nuevamente el vínculo entre verdad y felicidad que parece haber perdido, hace ya mucho tiempo, el pensamiento occidental.

\section{Conclusión}

Al pensamiento de Feyerabend no se le puede simplemente entender en el marco del escepticismo o como una mera radicalización de las consecuencias absurdas que se siguen de los supuestos de sus interlocutores. A lo largo de toda su obra nuestro autor procura entender, criticar y adquirir elementos para analizar la ciencia y su lugar en la vida del hombre. Ahora bien, que esa intelección haya sido, en mayor medida, negativa no debería ocultar el hecho de que nuestro autor va madurando paulatinamente, a través de una ampliación temática y metodológica, una visión o teoría positiva 
acerca de la ciencia. Pues en esta ardua tarea de comprensión el vienés se encontró con problemas que le mostraron lo erradas que eran las explicaciones que ofrecía en aquel entonces la filosofía de la ciencia. Estos problemas y contradicciones le permitieron descubrir la necesidad de emprender nuevos caminos para entender la ciencia.

En la sección 1, mostré una de las principales conclusiones que el vienés infiere de sus diatribas contra los distintos criterios de demarcación, a saber, que la búsqueda de un criterio de demarcación no es un camino efectivo para definir la ciencia. $O$, dicho de un modo positivo, que la ciencia debe entenderse o definirse como la suma de múltiples tendencias míticas, filosóficas y artísticas que interactúan recíprocamente. Los argumentos por los cuales procura reducir al absurdo a los criterios de demarcación le permitieron ver de una manera imperfecta lo que no es la ciencia, y por lo tanto, le señalaron, de algún modo, el camino o la dirección por la cual debía pensar su comprensión positiva acerca de la ciencia.

En la sección 2, expusé el relativismo que Feyerabend revindica durante un periodo. Expliqué que éste no sólo significa un cuestionamiento al humanismo de Popper, sino que también, y a través de dicha crítica, invita a practicar la ciencia de tal modo que se respete la felicidad y la libertad individual de cada uno de los ciudadanos. De este modo, esta etapa relativista puede explicarse positivamente como uno de los caminos por los que busca pensar una ciencia más humana.

Finalmente, en la sección 3, presenté su teoría positiva acerca de la ciencia tal como la formula en sus últimas obras. El giro hacia un relativismo cosmológico, el intento de elaborar una metafísica de la abundancia como intento de superar el historicismo de Kuhn — sin dejar por ello de subrayar el aspecto contextual de la ciencia-, el hecho de postular los valores humanos como los principios en virtud de los cuales debe ser juzgada la ciencia y las demás tradiciones de pensamiento, son todas elementos con los cuales Feyerabend supera y trasciende las posturas escépticas y relativistas que pudo haber sostenido en épocas anteriores.

\section{BIBLIOGRAFÍA}

Bird, A., 2001, "Review of Feyerabend by John Preston", Mind. New Series, vol. 110, no. 437, pp. 261-264.

Borrini, G., 1999, "Prefacio y reconocimientos", La conquista de la abundancia. La abstracción frente a la riqueza del ser, Paidós, Barcelona, pp. $\mathrm{xi}-\mathrm{xv}$. 
Bunge, M., 2003, Cápsulas, Gedisa, Barcelona.

Downes, S., 2002, "BookReview of Conquest of Abundance: A Tale of Abstraction Versus the Richness of Being, The Worst Enemy of Science? Essays in Memory of Paul Feyerabend, Science, Technology and Human Values, vol. 27, no 1, pp. 160-164.

Farrell, R., 2003, Feyerabend and Scientific Values. Tightrope-Walking Rationality, Kluwer Academic Publishers, Países Bajos.

Feyerabend, P., 2013a/1963, "Carta a Jack J.C. Smart", en Feyerabend 2013b, pp. 284-294.

— $2013 \mathrm{~b} / 1970$, Filosofía natural, Debate, Buenos Aires.

, 2013c/1977, "Solicitud de un año sabático", en Feyerabend 2013b, pp. $295-310$.

—_, 2008a/1993, Against Method, 3a ed., Verso, Londres.

, 2008b/1993, "Postscript on Relativism", en Feyerabend 2008a, pp. 268-272.

—, 2005/1987, Adiós a la razón, tercera edición, Tecnos, Madrid.

— 2003/1991, Provocaciones filosóficas, Editorial Biblioteca Nueva, Madrid.

—, 2000/1989, Diálogos sobre el Método, 2a. ed., Cátedra, Madrid.

_ , 1999a/1963, "How to Be a Good Empiricist: A Plea for Tolerance in Matters Epistemological", en Preston (ed.) 1999, pp. 78-103.

-, 1999b/1968, "Outline of Pluralistic Theory of Knowledge and Action", en Preston (ed.) 1999, pp. 104-111.

—_, 1999c/1975, "Let's Make More Movies", en Preston (ed.) 1999, pp. 192-199.

- $1999 \mathrm{~d} / 1977$, "Rationalism, Relativism and Scientific Method", en Preston (ed.) 1999, pp. 200-211.

—, $1999 \mathrm{e} / 1975$, "How to Defend Society Against Science", en Preston (ed.) 1999, pp. 181-191.

— , 1999f/1980, "Democracy, Elitism and Scientific Method", en Preston (ed.) 1999, pp. 212-226.

$-1999 \mathrm{~g} / 1994$, La Conquista de la abundancia. La abstracción frente a la riqueza del ser, Paidós, Barcelona.

— $1999 \mathrm{~h} / 1996$, Ambigüedad y armonía, Paidós, Barcelona.

—, 1996, "Theoreticians, Artists and Artisans", Leonardo: Journal of the International Society for the Arts, Sciences and Technology, vol. 29, no. 1, pp. 23-28. drid.

, 1993/1978, ¿Por qué no Platón?, Tecnos, Madrid.

- 1992/1975, Tratado contra el método. Esquema de una teoría anarquista del conocimiento, Tecnos, Madrid.

_, 199la, Three Dialogues on Knowledge, Basil Blackwell, Cambridge.

—_, 1991b, Diálogos sobre el conocimiento, Cátedra, Madrid. 
Feyerabend, P., 1991c, "Concluding Unphilosophical Conversation", Beyond Reason: Essays on the Philosophy of Paul Feyerabend. Boston Studies in the Philosophy of Science, Volume 132, en G. Munévar (ed.), Kluwer, Dordrecht, pp. 487-527.

- 1989/1970, Contra el método. Esquema de una teoría anarquista del conocimiento, Ariel, Barcelona.

- 1987, "Reason, Xenophanes and the Homeric Gods", The Kenyon Review, vol. 9, no. 4, pp. 12-22.

, 1982/1978, La ciencia en una sociedad libre, Veintiuno Editores S.A., Madrid.

- 198la, Realism, Rationalism and Scientific Method, Philosophical Papers Volume 1, Cambridge University Press, Cambridge.

- 1981b, Problems of Empiricism. Philosophical Papers Volume 2, Cambridge University Press, Cambridge.

-, 1981c, "Introduction: Scientific Realism and Philosophical Realism", en Feyerabend 1981a, pp. 3-16.

—, 1981d, "Introduction to volumes 1 y 2", en Feyerabend 1981b, pp. vii-xii.

- 1981e, "Historical Background: Some Observations on the Decay of the Philosophy of Science", en Feyerabend 1981b, pp. 1-33.

- , 1981f, "More Clothes from the Emperor's Bargain basement: A Review of Laudan's Progress and Its Problems", en Feyerabend 1981b, pp. 231-246.

- 198lg/1958, “An Attempt at a Realistic Interpretation of Experience", en Feyerabend 1981a, pp. 17-36.

_, $1981 \mathrm{~h} / 1960$, “On the Interpretation of Scientific Theories", Feyerabend 1981a, pp. 37-43.

_, 1981i/1964, "Realism and Instrumentalism: Comments on the Logic of Factual Support", en Feyerabend 1981a, pp. 176-202.

- 1981j/1965, "Reply to Criticism. Comments on Smart, Sellars and Putnam", en Feyerabend 1981a, pp. 104-131.

—, 1981k/1964, "Realism and Instrumentalism: Comments on the Logic of Factual Support”, en Feyerabend 1981a, pp. 176-202.

- 1976, "Logic, Literacy and Professor Gellner", British Journal for the Philosophy of Science, vol. 27, pp. 381-391.

, 1967, "On the Improvement of the Sciences and the Arts, and the Possible Identity of the Two", Proceedings of the Boston Colloquium for the Philosophy of Science, 1964-1966, en Memory of Norwood Russell Hanson, Boston Studies in the Philosophy of Science, Volume III, en Robert S. Cohen, Marx W. Wartofsky (eds.), D. Reidel, Dordrecht, pp. 387-415.

—, 1965, "Problems of Empiricism", Beyond the Edge of Certainty. Essays in Contemporary Science and Philosophy, en R. Colodny (ed.), CPS Publications in the Philosophy of Science, Pittsburg, pp. 145-260. 
Feyerabend, P., 1963a, "Review of Erkenntnislehre, by Victor Kraft", British Journal for the Philosophy of Science, vol. 13, no. 52, pp. 319323.

, 1963b, "Materialism and the Mind-Body Problem", The Review of Metaphysics, vol. 17, no. 1, pp. 49-66.

-, 1958, "Complementarity", Proceedings of Aristotelian Society, Suppl. vol. 32, pp. 75-104.

Gargiulo, T., 2016a, "El relativismo de Feyerabend", Ideas y valores (en prensa).

— 2016b, "Lo humano como valor epistémico. Apuntes en torno a la obra tardía de Paul Karl Feyerabend", Universum (en prensa).

— , 2015a, “Qué entiende Feyerabend por Metafísica?”, Ágora. Papeles de Filosofía, vol. 34, no. 1, pp. 59-86.

, 2015b, "La doctrina de la inconmensurabilidad en Paul Feyerabend: Una objeción contra una particular concepción de racionalidad científica", Areté. Revista de Filosofía (en prensa).

_, 2015 c, "Las implicancias de la proliferación teórica en la relación ciencia-metafísica", Revista Anales del Seminario de Historia de la Filosofía, vol. 32, no. 1, pp. 221-258.

— , 2015d, "Paul Karl Feyerabend y Thomas Kuhn en torno al problema del relativismo. Relativismo o una metafísica de la abundancia", Estudios Filosóficos, vol. 64, no. 186, pp. 255-279.

— , 2014a, "El anarquismo epistemológico de Paul Karl Feyerabend. Una reductio ad absurdum del positivismo lógico y del racionalismo crítico", Aporía, vol. 2014, no. 7, pp. 63-85.

—, 2014b, "El caso Galileo o las paradojas de una noción positivista de ciencia según Paul Karl Feyerabend", Revista Tópicos, vol. 47, no. 2, pp. 53-88.

— 2014c, "La crítica de Paul Karl Feyerabend al modelo neo-positivista del significado", Arbor. Ciencia, pensamiento y cultura, vol. 190, no. 769, al68.

—, 2012a, "Medicina y filosofía: ¿dos disciplinas o un único arte cognoscitivo?", Revista Philosophia, vol. 72, pp. 29-48.

— , 2012b, "Algunas reflexiones de Paul Karl Feyerabend en torno a los supuestos metafísicos del principio de complementariedad de Bohr", Revista Colombiana de Filosofía de la Ciencia, vol.12, no. 25, pp. 7-36.

Hacking, I., 1994, "Paul Feyerabend, Humanist", Common Knowledge, vol. 3, no. 2, pp. 23-28.

Harris, J., 1992, Against Relativism: A Philosophical Defense of Method, La Salle, Open Court.

Heit H., y E. Oberheim, 2013, "Paul Feyerabend como filósofo de la naturaleza. Introducción", Filosofía natural, Debate, Buenos Aires, pp. 9-35.

Hooker, C., 1991, "Between Formalism and Anarchism: A Reasonable Middle Way", Beyond Reason. Essays on the Philosophy of Paul Feye- 
rabend, en G. Munévar (ed.), Kluwer Academic Publishers, Dordrecht, pp. 41-107.

Hoyningen-Huene, P., 2000, "Paul K. Feyerabend. An Obituary", en Preston et al., 2000, pp. 3-15.

Jary, D., 1991, "Beyond Objectivity and Relativism: Feyerabend's 'Two Argumentative Chains' and Sociology", The Social Horizon of Knowledge: Poznan Studies in the Philosophy of Sciences and the Humanities Vol. 22., en P. Buczkowski (ed.), Rodopi, Amsterdam, pp. 39-57.

Kadvany, J., 1996, "Reason in History: Paul Feyerabend's Autobiography”, Inquiry, vol. 39, pp. 141-146.

Lloyd E., 2000, "Feyerabend, Mill, and Pluralism", en Preston et al. 2000, pp. 115-124.

Lyotard, J., 1991, La condición postmoderna, Teorema, Buenos Aires.

Masías Nuñez, R., 2002, "La metodología en los tiempos de la posmodernidad", Colombia Internacional, vol. 53, no. 1, pp. 5-13.

Moulines C., 1996, "Las ideas básicas del estructuralismo metacientífico", Revista de Filosofía. Tercera época, vol. 9, no. 16, pp. 93-104.

Munévar, G., 2006, Variaciones filosóficas sobre temas de Feyerabend, en Germán Guerrero Pino (comp.), Programa editorial Universidad del Valle, Caracas.

- 2000, "A Rehabilitation of Paul Feyerabend", en Preston et al. 2000, pp. 58-79.

-(ed.), 1991a, Beyond Reason. Essays on the Philosophy of Paul Feyerabend, Kluwer Academic Publishers, Dordrecht.

- 1991b, "Science in Feyerabend's Free Society", Beyond Reason. Essays on the Philosophy of Paul Feyerabend, Kluwer Academic Publishers, Dordrecht, pp. 179-198.

Musgrave, A., 1978, "Evidential Support, Falsification, Heuristics, and Anarchism", Progress and Rationality in Science, en G. Radnitzky, G. Andersson (eds.), Reidel, Dordrecht, pp. 181-201.

Neto, J., 1991, "Feyerabend's Skepticism", Studies in History and Philosophy of Science, vol. 22, no. 4, pp. 543-555.

Nickels, T., 1998, "La epistemología según Feyerabend", Cinta de Moebio, vol. 4, no. 4, pp. 123-129.

Oberheim, E., 2006, Feyerabend's Philosophy, Quellen Und Studien Zur Philosophie, Walter de Gruyter, Berlín.

Oberheim, E., P. Hoyningen-Huene, 2000, “Essay Review of John Preston's Feyerabend: Philosophy, Science and Society (Cambridge Polity 1997)", Studies in History and Philosophy of Science, vol. 31, pp. 363-375.

Preston, J., 2000, "Science as Supermarket: 'Post-Modern' Themes in Paul Feyerabend's Later Philosophy of Science", en Preston et al. 2000, pp. 80-101.

Preston, J., G. Munévar y D. Lamb (eds.), 2000, The Worst Enemy of Science? Essays in Memory of Paul Feyerabend, Oxford University Press, Nueva York. 
Preston, J. (ed.), 1999, Paul K. Feyerabend: Knowledge, Science and Relativism. Philosophical Papers Volume 3, Cambridge University Press, Cambridge,

Preston, J., 1999, "Introduction", en Preston 1999 (ed.), pp. 1-14. 1997a, Feyerabend. Philosophy, Science and Society, Blackwell, Oxford.

— , 1997b, "Feyerabend's Retreat from Realism", Philosophy of Science, vol. 64, no. 4, pp. 421-431.

Reaven, S., 2000, “Time Well Spent: On Paul Feyerabend's Autobiography", en Preston et al. 2000, pp. 16-27.

Russell, D., 1983, "Anything Goes", Social Studies of Science, vol. 13, no. 3, pp. 437-364.

Terrén, E., 1999, “Posmodernidad, legitimidad y educación”, Educação \& Sociedade, año XX, no. 67, pp. 11-47.

Tula Molina F., 2006, "Ideales de conocimiento y problemas epistemológicos: el caso del realismo feyerabendiano", Conocimiento, realidad y relativismo, en C. Di Gregori, M. Di Berardino (comps.), Universidad Nacional Autónoma de México, México, pp. 26-40.

Vásquez Rocca, A., 2005, "Postmodernidad y sobreinterpretación. Lecturas paranoicas y métodos obsesivos de interpretación", Nómadas, 11.

[< http://www.ucm.es/info/nomadas/11/avroccal.htm $>$. Fecha de consulta: $02 / 04 / 2013$.

Watkins, J., 2000, Feyerabend among Popperians 1948-1978, en Preston et al. 2000, pp. 47-57.

Zanotti, G., 2005, "Feyerabend y la dialéctica del iluminismo", Studium, tomo 8, fasc. 16, pp. 215-238.

Recibido el 16 de diciembre de 2013; revisado el 10 de febrero de 2015; aceptado el 11 de mayo de 2015. 